\title{
THE COAGULABILITY OF BLOOD IN RELATION TO CORONARY HEART DISEASE
}

\author{
By C. Merskey, M.D.(Cape), M.R.C.P.(London) \\ Senior Lecturer and Physician, Department of Medicine, Groote Schuur Hospital and University of Cape Town \\ and H. LACKNER, M.D.(Leeds), M.R.C.P.(London) \\ Part-time Lecturer and Assistant Physician, Department of Medicine and Groote Schuur Hospital
}

It is generally agreed that atheroma of the coronary artery, complicated by thrombosis of that : vessel, is the usual cause of myocardial infarction, but in some cases infarction can apparently occur without thrombosis. What part does coagulation of the blood play in coronary artery disease? Is it important in the pathogenesis of atheroma-is it, for instance, one of the underlying mechanisms in the production of the atheromatous plaque? How important is the actual formation of a thrombus in the coronary vessel in an acute infarct? What evidence is there that alteration in blood coagulability plays a part in the development (or lack of development) of the disease in an individual or a group of individuals? Is there a relationship between alterations in blood lipids, which can occur normally or be brought about by dietary and other means, and demonstrable alterations in the blood coagulating mechanisms?

If blood coagulation is important in some of these respects it might, for instance, lend added support to the use of anticoagulants for the prevention of recurrent coronary thrombosis or myocardial infarction. It would also justify attempts to ensure prevention of the initial thrombosis in people who, for reason of age, sex, family history and the presence of recognizable atherosclerosis in other parts of the body, might be regarded as especially at risk of coronary thrombosis. If it could be shown, for example, that there is a positive association between serum-cholesterol levels and liability to clot, this would provide additional justification for attempting to lower the serum-cholesterol level in patients at risk whose serum cholesterol is well above the mean for age and sex. Methods for the reduction of serum cholesterol might include dietary manipulation and particularly the modification of the quantity and quality of the dietary fat.

For all these reasons there has been a surge of interest in the study of blood coagulability and the mechanisms of coagulation and anticoagulation in relation to the pressing problem of ischaemic heart disease. Conclusions at this stage must be tentative and form the basis rather for further research than for immediate application.

Thrombosis may act in two ways. In the first place it may be responsible for intimal thickening which could be the basis of the atheromatous plaque and, secondly, it could add to atheroma and so be part of the mechanism of final closure of the artery. Rokitansky (184I) stated that the deposit in the artery in atheroma is an endogenous product derived from the blood and for the most part from the fibrin of the original blood. Duguid (I946) revived and elaborated this theory, claiming that a mural thrombus forming in an artery could become covered with endothelium and, on subsequently becoming organized, form a fibrous thickening of the intima. Mural thrombi, he claimed, especially of the red type, commonly underwent fatty change and assumed the characters of atherosclerotic plaques. He believed that there was good evidence that a considerable proportion of the lesions classified as atherosclerosis were altered thrombi (Duguid and Robertson, I957). Morgan (1956) and others also supported this view. Levene (1955, 1956) reported that apparently collagenous plaques of intimal thickening, when examined with the electron microscope, consisted mainly of fibrin. This could support the thrombogenic theory of atherogenesis, since it is not easy to explain in any other way the presence of fibrin in this situation. This explanation of the pathogenesis has not gone unchallenged (Keech and Reed, 1955; van den Hoof, 1955, 1956). It is also conceivable that the fibrin is derived from intimal haemorrhage which has been held to precede the atheromatous plaques as has been stressed by Paterson (1938) and others. Few would deny the importance of age and local strain or tension (Duguid, 1926; Muir, 1951). This is well shown by the presence of atheroma around 
openings of the intercostal vessels in the aorta and the greater amount of atheroma which develops in hypertension. But one cannot ignore the presence of excess cholesterol and other lipids in the blood and many would feel that these play a major part in the production of atheroma for they are, sooner or later, deposited in the artery. There is an associated local reaction with the production of fibrous tissue and the atheromatous plaque develops. We would agree with this concept of the aetiology of atheroma; in it thrombosis would :spear to play only a minor part.

While it is arguable that thrombosis is important in the causation of atheroma it is not disputed that it is often the final step in the closure of the coronary artery. It is not always so. Levine and Brown (1929), for example, examined 44 cases of myocardial infarction and found 23 occluded by a definite thrombus while 12 showed narrowing without thrombosis. In a recent study, Branwood and Montgomery (1956) found that 29 out of $6 I$ recent infarcts had thrombi but only 13 of these (2I per cent.) were fully occlusive; in addition, occlusion by soft atheroma, by the breakdown of an atheromatous patch, had occurred almost as frequently. They considered that, by the usual histological criteria it seemed that the thrombi were not the cause but were a terminal event in some of these cases of infarction. Boyd (1953) lists the causes of coronary occlusion in order of frequency as: (1) atheroma, (2) haemorrhage into the intima, (3) rupture of an atheromatous plaque, and (4) thrombosis. We believe that there are a multitude of factors operating; these have a varying validity in different cases. A familial tendency, hypercholesterolaemia, and a variety of local factors appear to be concerned. Thrombosis again only seems to play a small part in the initiation of the atheromatous plaque, but it is certainly part of the mechanism of final closure of the artery.

While local abnormalities in the lumen of the vessel may provoke thrombosis it is less certain that a generalized tendency to more rapid coagulation of the blood also plays a part. One of the difficulties is that it is not easy to demonstrate in vitro such a hypercoagulable state. The normal fluidity of the blood is determined by a delicately balanced mechanism and many factors could upset this balance and so predispose to thrombosis. Blood is especially liable to clot in vessels whose endothelial surface is damaged by disease or whose lumen is diminished by the thickening of the wall. Stasis and slowing of the blood stream may be important factors in the precipitation of a thrombus. In artificial tubular systems there are variations in marginal flow when the channels are tortuous, angulated or of varying calibre (Rodbard,
1956). In a patient in whom enough unfavourable circumstances coexist pathological thrombosis may occur (Biggs and Macfarlane, I957).

Certain conditions are notoriously associated $\stackrel{\varrho}{C}$ with pathological thrombosis in veins, e.g. malignant disease, leukaemia, post-puerperal and post- $\frac{9}{9}$ operative states. If a state of increased coagulability of the blood exists one might expect to be able to show it in one or other of these conditions. Many authors claim to have shown an increased tendency of the blood to clot. It has been asserted, for example, that patients who develop a thrombus have a shortening of the whole bloodclotting time (Cummine and Lyons, r948; Barker and Margulies, I949; Warren, 1953); tests using heparin in vivo or in vitro have been said to be abnormal (de Takats, r943; Hagedorn and Barker, 1948); ' fibrinogen B' has been said to be increased (Cummine and Lyons, 1948). All these claims have been denied (Ingram, Biggs and Armitage, 1953; Paterson and McLachlin, 1954). Hurn, Barker and Mann (1947) were unable to find a consistent variation in prothrombin or antithrombin in patients with thrombosing tendencies when compared with normal.

It has been claimed that patients with acute myocardial infarction may have phases during which the blood changes from a hypercoagulable state through a phase of reduced coagulability tê reach a stage of late hypercoagulability (Beaumont Chevalier and Lenègre, r953). Alternatively, patients with acute myocardial infarction could be subdivided into those with evidence of accelerated coagulation, those with normal coagulation and those with retarded coagulation. Anticoagulant therapy would then only be given to those in whom the blood showed increased coagulation (Fitzgerald Peel, r956).

A rise in platelet count occurs post-operatively and post-puerperally as does increased platelet stickiness (Wright, I942); Moolton and coworkers (r949a, r949b) also claimed an increased platelet stickiness after cellular destruction in surgery, after trauma or after acute myocardial infarction and peripheral gangrene. This was not confirmed by others (Eisen, Tyson, Michael and Baumann, 1951). De Nicola (1953) claimed an increase in factor 7 in thromboembolic disease and in late pregnancy, the latter finding also being reported by Koller (1954) and Alexander (1955), but there is little evidence that the increase in this factor has anything to do with an increased tendency to thrombosis. There are claims to have demonstrated a state of altered blood coagulability in patients with established ischaemic heart disease. In one series a ' heparin loading test ' has been said to reveal a hypercoagulable state (Ulutin and Sestakof, 1958). McDonald and Edgill (1957) 
claimed an increase in blood coagulability in a group of patients with ischaemic heart disease compared with healthy controls. This was based on greater thromboplastin generation, faster prothrombin time (using Russell Viper Venom as thromboplastin), increased plasma fibrinogen and increased platelet stickiness. We (Merskey, Gordon and Lackner, 1958, 1959) found no difference in the prothrombin time (using Russell viper venom as thromboplastin), but there was a little greater thromboplastin generation in the coronary group. We confirmed that patients over the age of 50 with established ischaemic heart disease have a higher plasma fibrinogen than similar age-matched controls. We did not estimate platelet stickiness. In any case, as McDonald and Edgill are careful to point out, these effects may be a result of the disease rather than a cause. One of the great difficulties is that the so-called age-matched ' control' group contains many individuals with occult coronary artery disease. In an attempt to overcome this difficulty we tested Bantu subjects (in whom coronary artery disease is rare) and found these to have diminished prothrombin and factor 7 and in this respect their blood might be considered less coagulable. Curiously there seemed to be an increase in the antihaemophilic factor in Bantu plasma as well as more efficient prothrombin consumption, and in this regard this blood was possibly more coagulable. Thromboplastin generation was equal to that of the coronary group and more than the controls. We thus found very little to support the thesis that the relative immunity to coronary artery disease of the Bantu was caused by any diminution in the tendency of the blood to clot; one might even claim that their blood had a greater tendency to clot.

In summary, therefore, one can say that though there have been many claims to have demonstrated increased coagulability of the blood in thrombotic (or potentially thrombotic) states, there is no unanimity of opinion on the subject and the case can by no means be considered as established. The evidence against increased coagulability of the blood is no less convincing than the evidence in its favour. This subject has recently been reviewed by Poole (1958).

Approaching the problem from a completely different direction, one could consider the effect of mechanisms which inhibit coagulation or which remove clots once they are forming or have formed. Anticoagulant therapy is widely used in atheromatous conditions and many believe it exerts a beneficial effect. Despite some unrepentant sceptics like McMichael (1958) it is probable that the patient who has an acute coronary thrombosis has a better chance of coming out of hospital alive if he has anticoagulant therapy than if he does not. One should, however, be wary of citing this as evidence that 'clotting' plays a part in this disease. A large number of anticoagulant drugs have been claimed to be effective; this is perhaps the best evidence we have. It seems hardly likely that they all work by means of some other, as yet, unidentified action. Even so, do they necessarily save lives by preventing coronary thrombosis? Honey and Truelove (1957), after a careful analysis, concluded that the overall effect of anticoagulant therapy on the fatality rate of acute coronary thrombosis has not been very great and the improvement could be accounted for by the almost complete abolition of deaths from pulmonary embolism.

If Duguid is right there would, perhaps, be justification for long-term anticoagulant therapy. Here, too, there are very conflicting claims. There is very little evidence that anticoagulants can remove pre-existing thrombi. Wright, Kubik and Hayden (1953) and Wright (1954) showed that oral anticoagulants (ethyl-biscoumacetate or phenindione) could cause disappearance of artificially produced thrombi in the femoral arteries of rabbits, while Loewe and Hirsch (1947) showed that heparin caused clots in jugular veins of rabbits to disappear. Nevertheless, many patients on longterm anticoagulant therapy have not been relieved of their angina (Gabrielsen and Myhre, I958; Manchester, 1957). As regards saving of life after long-term anticoagulant therapy, once again the evidence is not very good and is also conflicting. Suzman, Ruskin and Goldberg (1955) found these drugs to be life-saving especially when the presenting attack of infarction was severe and recurrent. Wright et al. (1954) and Manchester (1957) also found anticoagulants to be helpful when continued over a period of years. On the other hand, Bjerkelund (1957), in the best controlled study published to date, recorded benefit only during the first year of treatment and only in patients under the age of 60 years. One could, however, take issue with him when he compares the fate of survivors after the first year on anticoagulant therapy with the survivors who did not have such therapy, since the first group contains many who could otherwise have died and must, therefore, be rated as 'worse risks' from the beginning of the second year.

In summary we feel that anticoagulant drugs have probably made a difference to the prognosis of this disease in acute cases of coronary thrombosis as well as when these drugs are used continuously for long-term treatment. It is probable that the beneficial effect is mediated through an anticoagulant mechanism, though the mechanism of this is not, at the moment, very clear. 
It is now generally accepted that there exists in the blood a fibrinolytic enzyme which is capable of dissolving fibrin clots. The fibrinolytic activity of blood, as tested in vitro, is labile, and normally of a low order of activity. The relationship between fibrinolysis and coronary artery disease is at the moment largely speculative. It seems not very unreasonable to suppose that decreased fibrinolytic activity might play a part in the pathogenesis of atheroma. Artificially-induced fibrinolysis, on the other hand, may in the future prove to be of value in the removal of intravascular thrombi.

If one accepts Duguid's concept that atheroma is due to fibrin deposition in the lining of the arteries, it is only one step further to suggest that fibrinolytic activity may be concerned in the dissolution of these deposits, thus preventing their incorporation within the vessel wall and the production of atherosclerosis. Greig (1956) has shown that, following a fatty meal, the fibrinolytic activity of the blood is considerably diminished and suggested that this finding may be the connecting link between Duguid's theory and the reports that a diet rich in animal fats plays an important part in the production of atheroma. Moreover, Kwaan and McFadzean (1957) have shown that rabbits fed on a diet rich in cholesterol took four times as long to lyse artificially-produced venous thrombi, than did the normal controls. Both these claims are as yet unconfirmed. Even if they are true, we have very considerable reservations regarding their importance in this problem.

On comparing the fibrinolytic activity of the blood in a group of normal Bantu males in Durban with Greig's (1956) report on White controls in Johannesburg it was found that the Bantu had more fibrinolytic activity than the White (Gillman, Naidoo and Hathorn, 1957). In groups of Bantu and White males studied by ourselves, we (Merskey, Gordon and Lackner, 1958) found the mean clot lysis time for the Bantu group to be 5.6 hours and for the White control groups 10.4 hours, the difference being statistically highly significant $(\mathrm{P}<0.00 \mathrm{I})$. We were unable to demonstrate any difference between the clot lysis time of normal White controls and of patients who had undoubted ischaemic heart disease.

Since coronary artery disease is practically unknown in the Bantu, this finding could be held to support the concept that the lower fibrinolytic activity in the blood in White men may play a part in the production of atheroma, but the absence of a difference in our two White groups would require to be explained. Hume (1958), on the other hand, has shown that for 10 days following myocardial infarction there is marked depression and undue fluctuation of fibrinolysis. Whether this phenomenon is the cause or the result of the in- farction has not been established. The role that fibrinolysis plays in the aetiology of atheroma and $\bar{z}$

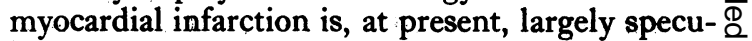
lative and we doubt whether it is of major $c$. significance.

Artificially-induced fibrinolysis may prove to be $\stackrel{\text { ज्ञ }}{+}$ an important advance in the treatment of intra- $\frac{}{0}$ vascular thrombosis. This work, which is still in $\frac{\bar{c}}{\bar{c}}$. its infancy, is being tackled from two different $\frac{\rho}{D}$ aspects. Meneghini (1958) stimulated the patients' $\cong$ own fibrinolytic system by injection of proteinfree pyrogenic lipopolysaccharides. This is asso- $\vec{O}$ ciated with considerable constitutional upset, which is incompletely controlled by administration $\vec{\omega}$ of salicylate. Results seem to be encouraging, $\frac{\Omega}{\circ}$ especially in cases of venous thrombosis, but this method is not suitable in cases of coronary thrombosis because of the unpleasant and severe side- ${ }_{-T}$ effects. Cliffton, Grossi and Cannamela (1954) $\hat{o}^{\circ}$ and Back, Ambrus, Goldstein and Harrison (1956), N on the other hand, injected a previously prepared $\stackrel{\mathrm{C}}{\mathrm{C}}$ fibrinolysin (plasmin) in the form of streptokinase- 0 streptodornase (SK-SD) activated plasminogen. Again results are better in cases of venous throm- $\vec{D}$ bosis than in those of arterial thrombosis. Untoward side reactions in the form of chills, fever, cyanosis and hypotension seem to be related 0 an excess of SK-SD and can be somewhe diminished by using less activator. Since to reactions with this method are less severe, the is hope that a non-toxic preparation might be developed which could be used in the treatment of coronary thrombosis.

The part that blood lipids play in the problem $\stackrel{\vec{F}}{\vec{F}}$ of ischaemic heart disease is reviewed elsewhere $\frac{3}{3}$ (Bronte-Stewart, 1958). What part do they play in blood coagulation? Heparin, for instance, has: a 'fat-clearing action' as well as an anticoagulant action. It was hoped that a study of the Bantu 3 . might reveal differences in blood coagulation, $\dot{\sigma}$ since the Bantu have both less serum cholesterol and less coronary artery disease. The somewhat $\delta$ confusing results have already been discussed. In 3 rabbits, if the plasma cholesterol is raised to ex-응 cessive levels, there is a diminished tendency of $\rightarrow$ the blood to clot while at the same time cholesterolosis of the aorta develops (Merskey, 1957). Rats fed large amounts of cholesterol and fat and 5 thiouracil form thrombi in the coronary vessels 0 and develop myocardial infarction (Hartroft and $\mathcal{\omega}_{\mathrm{N}}^{N}$ Thomas, 1957). None of these observations ap- -0 pears to have any direct bearing on human disease.

There is a little evidence on the effect of an acute $\bar{\Phi}$ fat load on blood coagulation which is worth men- $\stackrel{\oplus}{+}$ tioning. It is not difficult to show that fat added 0 to blood in a test tube materially accelerates blood 0

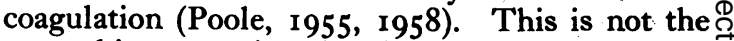
same thing as saying that fat taken by mouth can $\stackrel{\mathbb{Q}}{\Omega}$ 
have this effect. Waldron and co-workers (I95I, I954) claimed that ingested fats accelerated coagulation of blood, and similar claims were put forward by Fullerton, Davie and Anastasopoulos (1953), O'Brien (1955), Keys, Buzina, Grande and Anderson (1957), and by others. The coagulation time of the blood in silicone tubes was said to be shortened and so was the co-called 'Stypven' time (one-stage plasma thromboplastin time using Russell Viper Venom as thromboplastin). No effect of ingested fat on coagulation time of blood in silicone tubes could be shown by Tulloch, Overman and Wright (1953), by Manning and Walford (1954), by Sheehy and Eichelberger (1958), by Borrero, Sheppard and Wright (1958), by Merskey and Nossel (1957), or by Sohar, Rosenthal and Adlersberg (1957). These last two groups of workers also used a large number of other tests of coagulation efficiency without obtaining convincing evidence of the effect of postprandial hyperlipaemia on blood coagulation. Curiously enough, even O'Brien (1955), who claimed that fat shortened the coagulation time, could not demonstrate any correlation between this shortening and the changes in the total ether extractable fatty acids in the plasma or the opacity of the plasma. Nor could he demonstrate a difference in the reaction of coagulation time to an acute fat load in normal subjects and those with coronary artery disease (O'Brien, 1958). All workers agreed that fat taken by mouth shortened the Stypven time, especially in platelet-poor plasma (or in platelet-containing plasma if the platelets had not been allowed to rupture and release their contained phospholipid). Much energy was expended in identifying the fat which was responsible for the effect and there were many conflicting results. In 1936 Trevan and Mcfarlane showed that the addition of crude lecithin to recalcified citrate plasma with Russell Viper Venom accelerated clotting. Ethanolamine phosphatide has the same action as crude lecithin and it seems to have the same effect on enhancing thrombin formation whether it is prepared synthetically or whether it is derived from brain or egg yolk (Poole and Robinson, 1956). O'Brien (1957), who has reviewed this subject extensively, feels that it is likely that the post-prandial acceleration of the Stypven time could be due to the presence in the plasma of any one of a number of identified, or as yet unidentified, phospholipids. But many would query the validity of conclusions based on such an artificial test as the Stypven time. It is sensitive to the presence of fat, but there is hardly any evidence that it plays a part in vivo. Finally, while fats of different degrees of saturation or unsaturation have varying effects on the serumcholesterol level the degree of saturation seems to play little part in this Stypven time (Merskey and Nossel, I957; O’Brien, I957), since both saturated and unsaturated fats may shorten the Stypven time.

This brief and admittedly very incomplete review shows how little concrete evidence there is that alterations in the coagulability of the blood play a part in the pathogenesis of coronary atheroma and in the production of ischaemic heart disease. It remains an attractive theory, but the evidence in favour of it is scanty. The techniques of assaying coagulation which we have at our disposal are crude and sensitive to a host of extraneous factors. They must be done with meticulous care, be adequately (and even, perhaps, excessively) controlled, and even then looked at with a somewhat sceptical eye. Possibly one day we may have other techniques available, more sensitive, more reproducible and, perhaps, even more meaningful. Until that time we would be well advised to conclude that while fat, atheroma and blood coagulation may be linked in some way, available evidence is insufficient for us at the moment to draw any definite conclusions.

\section{BIBLIOGRAPHY}

ALEXANDER, B. (1955), New Engl. F. Med., 252, 526.

BACK, N., AMBRUS, J. L., GOLDSTEIN, S., and HARRISON, J. W. E. (1956), Circulation Research, 4, 440.

BARKER, N. W., and MARGULIES, H. (1949), ' Blood Clotting and Allied Problems,' Transactions 2nd Conference Josiah Macy, Jnr., Foundation, p. 106.

BEAUMONT, J. L., CHEVALIER, H., and LENEGRE, J. (1953), Amer. Heart $\mathcal{F} ., 45,756$.

BIGGS, R., and MACFARLANE, R. G. (I957), ' Human Blood Coagulation and Its Disorders,' Blackwells, Oxford.

BJERKELUND, C. J. (1957), Acta. med. scand., 158, suppl. 330.

BORRERO, J., SHEPPARD, E., and WRIGHT, I. S. (1958), Circulation, 17, 936.

BOYD, W. (1953), 'A Textbook of Pathology,' 6th ed., p. 324, Henry Kimpton, London.

BRANWOOD, A. W., and MONTGOMERY, G. L. (1956), Scottish M. F., I, 367.

BRONTE-STEWART, B. (1958), this Journal, p. ooo.

CLIFFTON, E. E., GROSSI, C. E., and CANNAMELA, D. (1954), Ann. Surg., 139, 52.

CUMMINE, H., and LYONS, R. N. (1948), Brit. F. Surg., 35, 337.

DUGUID, J. B. (1926), f. Path. Bact., 29, 37 r.

DUGUID, J. B. (1946), Ibid., 58, 207.

DUGUID, J. B., and ROBERTSON, W. B. (1957), Lancet, i, 1205.

EISEN, M. E., TYSON, M. C., MIĆHAEL, S., and BAUMANN, F. (1951), Circulation, 3, 271 .

FULLERTON, H. W., DAVIE, W. J. A., and ANASTASOPOULOS, G. (r953), Brit. med. $\mathscr{F}$., ii, 250.

GABRIELSEN, Z., and MYHRE, J. R. (1958), Circulation, 17, 348.

GILLMAN, T., NAIDOO, S. S., and HATHORN, M. (1957), Lancet, ii, 696.

GREIG, H. B. W. (1956), Ibid., ii, I6.

HAGEDORN, A. B., and BARKER, N. W. (1948), Amer. Heart $\mathcal{F}$. 35,603 .

HARTROFT, W. S., and THOMAS, W. A. (1957), f. Amer. med. Ass., 164, 1899 .

HONEY, G. E., and TRUELOVE, S. C. (1957), Lancet, i, II 55.

HOOFF, A. VAN DEN (1955), Ibid., ii, 1392 .

HOOFF, A. VAN DEN (1956), Ibid., i, 247.

HUME, R. (1958), Brit. Heart F., 20, 15.

HURN, M., BARKER, N. W., and MANN, F. D. (I947), Amer, F. clin. Path., 17, 700 .

INGRAM, G. I. C., BIGGS, R., and ARMITAGE, P. (I953), F. clin. Path., 6, 46 .

KEECH, M. K., and REED, R. (1955), Lancet, ii, 1392.

Bibliography continued on page 222 
virtually no change in the prevalence of the disease measured electrocardiographically in the three racial groups during the period under review (1952 to 1957).

The effect of sex on the prevalence of infarction was again well borne out during 1957 in all races. Only 64 of the 262 cases in Whites were women, and 56 of these were 50 or over, with a peak prevalence between 60 and 69 . In the 79 Coloured cases, 22 were women, 17 were 50 and over, with a similar peak prevalence between 60 and 70 . No case of ischaemic heart disease has yet been encountered in a Bantu female. The peak incidence in White and Coloured males was between 50 and 59, with 27 per cent. of the Whites below 50 and 37 per cent. of the Coloureds. The only Bantu case was over 70 years old. These figures are very similar to those published for $195^{2}$ to $195^{6}$ (Schrire, 1958a).

\section{Conclusions}

Electrocardiograms of 3,525 adults attending the Groote Schuur Hospital and the New Somerset Hospital, Cape Town, during 1957 were analysed to determine the inter-racial prevalence of myocardial infarction.

Electrocardiographic evidence of myocardial in- farction was found in only one Bantu during 1957 and this patient had been seen before in previous years.

Electrocardiographic evidence of myocardial infarction and ischaemic heart disease was found far more commonly in the White than in the Cape Coloured, in both of whom the disease was common.

The higher prevalence of ischaemic heart disease in Whites than in non-Whites was confirmed and was not attributable to a significant difference in age distribution of the population studied.

The peak prevalence in males was between 50 and 59 and in females between 60 and 69. The disproportionate prevalence in males was confirmed.

The results were compared with the findings of previous years.

\section{BIBLIOGRAPHY}

CONYBEARE, J. (1952), Guy's Hosp. Gaz., 66, 421.

OSLER, W. (1910), Lancet, i, 697.

PATON, B. C. (1957), Amer. F. Med., 23, 76 r.

RYLE, J. A., and RUSSELL, W. T. (1949), Brit. Heart F., II, 370. SCHRIRE, V. (1958a), Amer. Heart f., 56, 280.

SCHRIRE, V. (1958b), S. Afr. med. F., 32, 177.

STOCKS, P. (I95I), Lancet, i, 35I.

THOMAS, A. J., COCHRANE, A. L., and HIGGINS, I. T. T. (1958), Ibid., ii, 540.

VOGELPOEL, L., and SCHRIRE, V. (1955), Ibid., ii, I 108.

Bibliography continued from page 207-C. Merskey, M.D.(Cape), M.R.C.P.(London), and H. Lackner, M.D.(Leeds), M.R.C.P.(London)

KEYS, A., BUZINA, R., GRANDE, F., and ANDERSON, J. T. (I957), Circulation, 15, 274

KOLLER, F. (1954), in 'Thrombosis and Embolism,' p. 112 , B. Schwabe and Co., Basel.

KWANN, H. C., and McFADZEAN, A. J. S. (1957), Nature, 179, 260.

LEVENE, C. I. (1955), Lancet, ii, 1216.

LEVENE, C. I. (1956), Ibid., i, 105.

LEVINE, S. A., and BROWN, C. L. (1929), Medicine, 8, 245.

LOEWE, L., and HIRSCH, E. (1947), F. Amer. med. Ass., 133, 1263.

MANCHESTER, B. (1957), Arch. intern. Med., 100, 959.

MANNING, P. R., and WALFORD, R. L. (1954), Amer. F. med. Sci., 228, 652.

McDONALD, L., and EDGILL, M. (I957), Lancet, ii, 457.

McMICHAEL, J. (1958), Ibid., i, 528.

MENEGHINI, P. (1958), Acta Haemat. (Basel), 19, 65.

MERSKEY, C. (I957), Brit. F. Haematol., 3, 366.

MERSKEY, C., GORDON, H., and LACKNER, H. (1958), S. Afr. med.' F., 32, 855 .

MERSKEY, C., GORDON, H., and LACKNER, H. (1959), to be published.

MERSKEY, C., and NOSSEL, H. L. (1957), Lancet, i, 806.

MOOLTEN, S. E., VROMAN, L., and VROMAN, G. M. S. (1949a), Amer. Э. clin. Path., 19, 814.

MOOLTEN, S. E., VROMAN, L., VROMAN, G. M. S., and GOODMAN, B. (1949b), Arch. intern. Med., 84, 667 .

MORGAN, A. D. (1956), 'The Pathogenesis of Coronary Occlusion,' Blackwells, Oxford.

MUIR, R. (1951), in 'Muir's Textbook of Pathology,' 6th ed., p. 293, Edward Arnold, London.

de NICOLA, P. (1953), 'Texas Report on Biology and Medicine,' II, 3 .

O'BRIEN, J. R. (1955), Lancet, ii, 690.

O'BRIEN, J. R. (1957), Amer. F. med. Sci., 234, 373.

O'BRIEN, J. R. (1958), Lancet, i, 410.

PATERSON, J. C. (1938), Arch. Path., 25, 474.
PATERSON, J. C., and McLACHLIN, J. (1954), Surg Gynec. Obstet., 98, 96.

PEEL, A. A. FITZGERALD (1956), Brit. Heart $\mathcal{F}$., 18, 378.

POOLE, J. C. F. (1955), Brit. F. exp. Path., 36, 248.

POOLE, J. C. F., and ROBINSON, D. S. (1956), Quart. F. exp. Physiol., 41, 295.

POOLE, J. C. F. (1958), Brit. med. Bull., 14, 253.

RODBARD, S. (1956), Circulation, 14, 483

ROKITANSKY, C. (1841), 'Manual of Pathological Anatomy, cited by Morgan (1956).

SHEEHY, T. W., and EICHELBERGER, J. W., Jnr. (1958), Circulation, 17, 927.

SOHAR, E., ROSENTHAL, M. C., and ADLERSBERG, D. (1957), Amer. F. clin. Path., 27, 503.

SUZMAN, M. M., RUSKIN, H. D., and GOLDBERG, B. (1955), Circulation, 12, 338 .

de TAKATS, G. (1943), Surg. Gynec. Obstet., 77, 31 .

TREVAN, J. W., and MACFARLANE, R. G. (1936), Report of the Medical Research Council for the year 1936-37, p. 143 .

TULLOCH, J. A., OVERMAN, R. S., and WRIGHT, I. S. (1953), Amer. F. Med., 14, 674 .

ULUTIN, O. N., and SESTAKOF, D. (1958), Lancet, i, 324.

WALDRON, J. M., BEIDELMAN, B., and DUNCAN, G. G. (195 I), Gastroenterology, 17, 360 .

WALDRON, J. M., and DUNCAN, G. G. (1954), Amer. F. Med., I7, 365 .

WARREN, R. (1953), New Engl. F. Med., 249, 99.

WRIGHT, H. P. (1942), f. Path. Bact., 54, 461 .

WRIGHT, H. P., KUBIK, M. M., and HAYDEN, M. (1953), Brit. med. $\mathcal{F}$., i, I021.

WRIGHT, H. P. (1954), in 'Thrombosis and Embolism,' p. 565, B. Schwabe and Co., Basel. WRIGHT, I. S., BOURGAIN, R. H., FOLEY, W. T., Mc-
DEVITT, E., LIEBERMAN, J., SYMONS, C., and HUEBNER, R. (I954), Circulation, 9, 748. 